\title{
Acute Promyelocytic Leukemia with FIt3-TKD and WT1 Mutations Relapsing in a Testicle and Followed by Systemic Relapse
}

\author{
Xing-li Zou ${ }^{a}$ Ke Zeng ${ }^{a}$ Li-ping Xie ${ }^{a}$ Lin Wang ${ }^{b}$ Min Chen ${ }^{b}$ Ting Liu ${ }^{a}$ \\ Ting Niu ${ }^{a}$ \\ ${ }^{a}$ Department of Hematology and Research Laboratory of Hematology, and bepartment of Pathology, \\ West China Hospital, Sichuan University, Chengdu, PR China
}

\section{Key Words}

Acute promyelocytic leukemia FLT3-TKD mutation .

Prognosis - Testicular relapse $\cdot$ WT1 mutation

\begin{abstract}
Extramedullary relapse is a rare phenomenon in patients with acute promyelocytic leukemia (APL), especially that derived from urogenital systems like the testicles. In this report, we describe an APL patient who had received standard induction/maintenance therapy resulting in durable remission for 4.5 years, when he presented with a unilateral testicular mass confirmed as myeloid sarcoma; this was followed by systemic relapse of APL. Retrospective analysis of the involved blood and bone marrow samples at the time of the initial diagnosis revealed a rare point mutation of FLT3TKD and a novel mutation of WT1. These mutations were detected recurrently throughout the course of the disease. After reinduction therapy with arsenic trioxide and all-trans retinoic acid combined with daunorubicin, complete hematological remission was achieved for the ensuing salvage allogeneic hematopoietic stem cell transplant.
\end{abstract}

(c) 2013 S. Karger AG, Basel

0001-5792/13/1304-0223\$38.00/0

\section{Introduction}

Acute promyelocytic leukemia (APL) is a distinctive subtype of heterogeneous myeloid malignancies with specific cytogenetic features, characterized by reciprocal translocation between chromosomes 15 and 17, which leads to generation of the PML-RARa fusion gene and product interfering with the maturation of myeloid cells. Patients with APL often have an outstanding response to all-trans retinoic acid (ATRA)/arsenic trioxide (ATO)based therapy, with a reported high 5-year disease-free survival rate of $74 \%$ [1]. However, some patients inevitably relapse even after adequate consolidation therapies. Similar to other types of myeloid leukemia, APL commonly relapses in the bone marrow; however, an increasing number of extramedullary (EM) recurrences have also been reported. Here we present an APL patient who underwent standard chemotherapy to achieve complete remission followed by routine monitoring of minimal residual disease for 4.5 years, when he presented with soli-

\section{X.Z. and K.Z. contributed equally to this work.}

Ting Niu

Department of Hematology and Research Laboratory of Hematology West China Hospital, Sichuan University, 37 Guo Xue Xiang Street, Chengdu, Sichuan, 610041 (PR China)

E-Mail tingniu1@sina.com 
tary testicular involvement prior to systemic relapse. In addition, we also retrospectively screened the preserved pathological samples for several predictive genetic markers that had been well established in acute myeloid leukemia (AML). A rare mutation (p.Asp839Gly, c.2516A>G) in the tyrosine kinase domain (TKD) of the FMS-like tyrosine kinase 3 gene (FLT3-TKD) and a novel Wilms' tumor 1 gene (WT1) mutation (p.Arg458Pro, c.1373G $>C$ ) were detected and found to be correlated with the disease biology. To our knowledge, this is the first report of testicular involvement prior to systemic recurrence of APL, indicating the importance of any EM abnormalities during follow-up and the genetic prognostic factors seldom detected in APL patients.

\section{Case Report}

A 32-year-old Chinese man presented to the hematology clinic because of bone pain and gingival bleeding. He was found to have a leukocytosis of $124.40 \times 10^{9} / 1$ consisting of $97 \%$ circulating promyelocytes, hemoglobin $(\mathrm{Hb})$ of $10.9 \mathrm{~g} / \mathrm{dl}$, and a platelet (PLT) count of $50 \times 10^{9} / 1$. The coagulation profile showed a prothrombin time (PT) of $15.8 \mathrm{~s}$ (normal range 11.8-14.8 s), an international normalization ratio (INR) of 1.31, an activated partial thromboplastin time (APTT) of $49.7 \mathrm{~s}$ (normal range 28-45 s), a thrombin time (TT) of $19.6 \mathrm{~s}$ (normal range 14-22 s), and fibrinogen (FIB) $1.74 \mathrm{~g} / \mathrm{l}$ (normal range 2.0-4.0 g/l). Bone marrow smear and biopsy showed neoplastic infiltration of promyelocytes containing bundles of Auer rods, and flow cytometric analysis revealed an aberrant myelogenous phenotype. The ATRA therapy was initiated immediately at a dose of $20 \mathrm{mg}$, twice a day, and the diagnosis of APL was confirmed by detection of the PML-RARa fusion gene in a bone marrow aspirate sample. At the beginning of induction therapy, daunorubicin (DNR; $60 \mathrm{mg} /$ day for 3 consecutive days) was added to the regimen, and ATO (10 mg/day for 22 days) was administered to replace ATRA. After nearly 40 days of induction therapy, the patient's bone marrow aspiration indicated morphologic complete remission, but the PML-RARa fusion gene remained detectable. After another 3 cycles of anthracycline-based consolidative chemotherapy (DA regimen, DNR $60 \mathrm{mg} /$ day on days 1-3 plus ATRA $20 \mathrm{mg}$, twice a day, on days 1-15), the patient achieved complete molecular remission. Thereafter, different regimens including ATO (10 mg/day for 14 consecutive days), ATRA (10 mg, thrice a day, for 28 days), and 6-mercaptopurine (50 mg, twice a day, for 28 days) plus methotrexate (MTX; $10 \mathrm{mg} /$ week, for 4 weeks) were given in succession as maintenance therapy for a total of 8 cycles over the next 2 years. The patient achieved durable remission verified by morphological and molecular examination of the bone marrow every 3 months. In addition, examination of cerebrospinal fluid and intrathecal injection of MTX or arabinosylcytosine were performed regularly, and no evident APL relapse was found during the 2-year maintenance therapy.

At 28 months from the last consolidation treatment, the patient observed slight enlargement of the right testicle. However, it was not thought to be significant at that time because of its asymptomatic progression and normal routine monitoring of minimal leu-

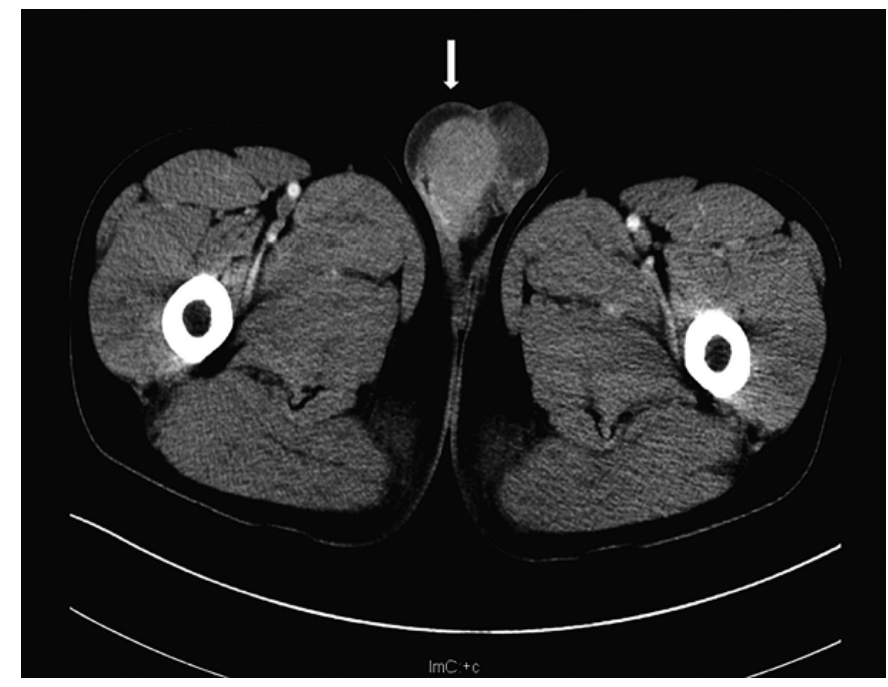

Fig. 1. CT scan revealed a mass with a size of $5.6 \times 4.0 \mathrm{~cm}$ with surrounding effusion at the right testicle (arrow).

kemia. Subsequently, at the 6-month follow-up, the right testicle became progressively more swollen and then the patient was referred to the Department of Urinary Surgery. A right testicular mass with abnormal density $(5.6 \times 4.0 \mathrm{~cm}$ in size $)$ was detected by computed tomography (CT) (fig. 1), indicative of secondary or therapy-related neoplasm. Restaging scans of the brain, chest, or abdomen did not show any evidence of relapse involvement. The patient's blood and coagulation tests were completely normal. The involved testicle was subsequently removed and the cut surface of the mass was gray-green. Corresponding pathological examination revealed that the testicle and ipsilateral spermatic cord were infiltrated by small malignant cells with granular cytoplasm (fig. 2a), which appeared to be homogeneously expressing myeloperoxidase (MPO) (fig. 2b) and lacking CD34 (fig. 2c) or CD117 (fig. 2d) by immunohistochemical (IHC) staining. Further detection of the PML-RARa fusion gene by fluorescence in situ hybridization (FISH) confirmed the testicular relapse of APL (fig. 3). However, consecutive evaluation of bone marrow morphology and corresponding $P M L-R A R a$ fusion gene detection were negative. Therefore, systemic therapy for APL relapse was not administered. At 1 month after orchiectomy, the patient presented to the hospital for spontaneous gingival bleeding unrelated to tooth brushing. He reported no concomitant fever, headache, or vomiting. A physical exam did not reveal any cutaneous petechiae. The laboratory tests showed $\mathrm{Hb} 14.4 \mathrm{~g} / \mathrm{dl}$, PLT $92 \times 10^{9} / \mathrm{l}$, and WBC $2.56 \times 10^{9} / \mathrm{l}$, with $3 / 50$ circulating blasts; coagulation function showed PT 15 s, INR 1.34, APTT 16.2 s, TT 27.4 s, and FIB $0.5 \mathrm{~g} / \mathrm{l}$. Bone marrow examination found $51 \%$ promylocytes and $11 \%$ blasts; flow cytometric analysis of the bone marrow showed 78\% blasts positive for CD117 (dim), CD123 (dim), CD13 (dim), and CD33 (dim), which partially expressed CD34 and HLA-DR. The $P M L-R A R a$ fusion gene was detected at a level of $9.5 \times 10^{5}$ copies/ $\mathrm{ml}(P M L-R A R a / A B L$ ratio $26.39 \%)$ in the bone marrow by quantitative PCR.

In order to understand the unusual relapse pattern of testicular involvement, we performed a series of mutational analyses aimed 

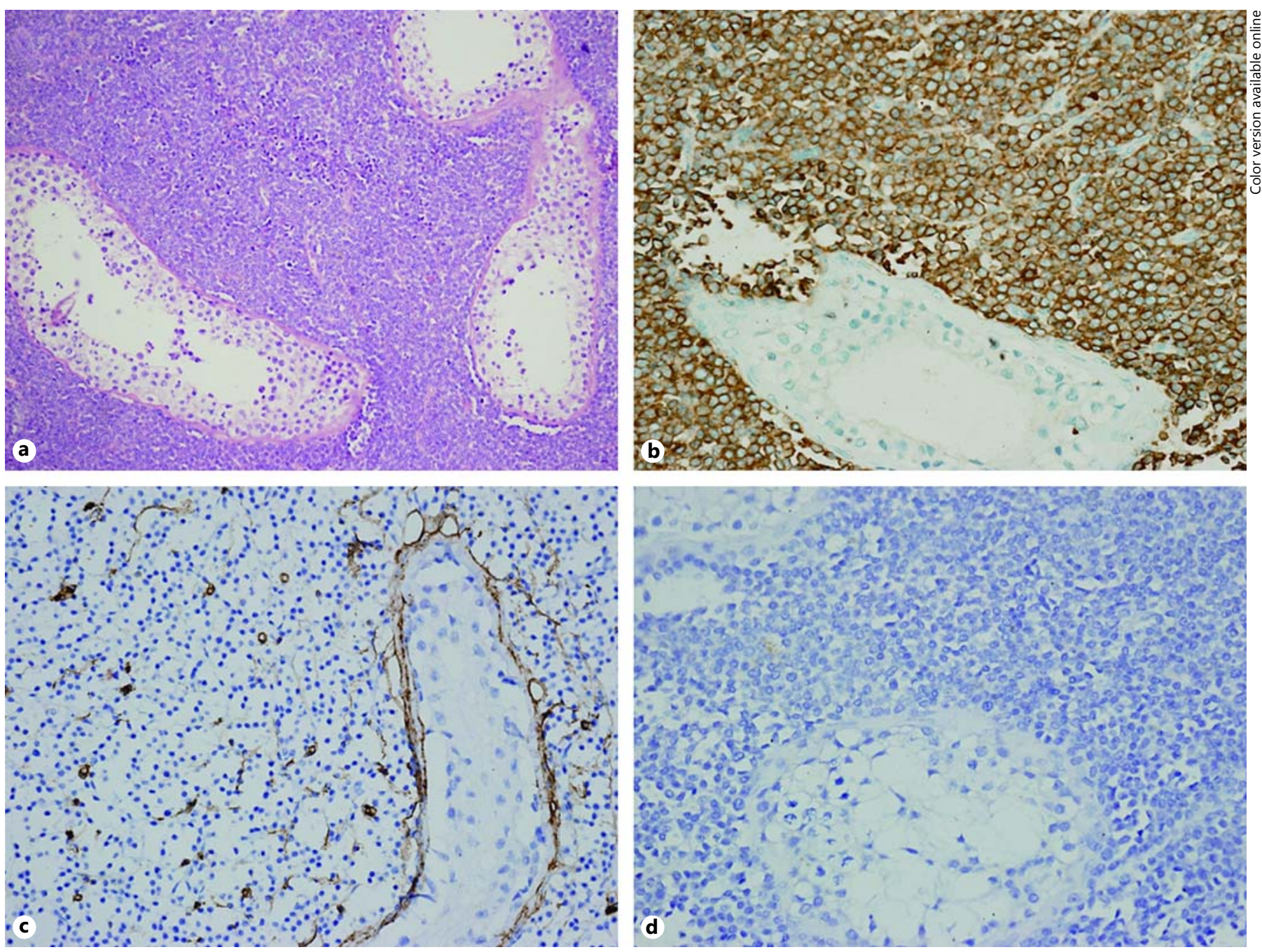

Fig. 2. Hematoxylin and eosin and IHC staining of the specimens from the involved testicle, supporting the EM myelogenous neoplasm. a H\&E staining. $\times 200$. b Cytoplasmic expression of MPO. $\times 400$. c IHC staining negative for CD34. $\times 400$. d IHC staining negative for CD117. $\times 400$.

at 11 prognosis-associated genes: CEBPA, DNAT3A, FLT3-ITD/ TKD, IDH1, IDH2, KIT, K-RAS, NPM1, N-RAS, TET2, and WT1, which ultimately lead to the identification of rare FLT3-TKD (fig. 4a) and novel WT1 (fig. 4b) point mutations. The mutations in FLT3-TKD and WT1 loci usually suggest opposite therapeutic responses and prognoses for general non-M3 AML but are seldom detected or interpreted for APL.

Considering that the patient may be at high risk of developing refractory APL with undefined genetic mutations, he was enrolled into the clinical trial of tamibarotene, a synthetic retinoid first approved to be used in relapsed/refractory APL in Japan. However, the patient was randomized to the control group receiving ATRA (20 mg twice a day) combined with ATO (10 mg/day). With the conventional regimen used as reinduction therapy, the patient's hypofibrinogenemia improved gradually and the differentiation of his aberrant promyelocytes to mature myeloid cells was demonstrated in peripheral blood examination. Although he had devel- oped serious fungal pneumonia during the induction therapy, bone marrow examination at day 40 indicated hematologic complete remission. The patient is planned to undergo contralateral testicle radiotherapy followed by allogeneic stem cell transplant (allo-HSCT) during the second remission for a better outcome.

\section{Discussion}

ATRA/ATO combined with anthracycline is a firstline regimen resulting in long-term survival for most APL patients. Nevertheless, relapse still occurs in approximately $20 \%$ of cases [2]. The majority of postremission relapses occur in the bone marrow, but approximately $3 \%$ could be present at EM sites $[3,4]$. The most frequently 

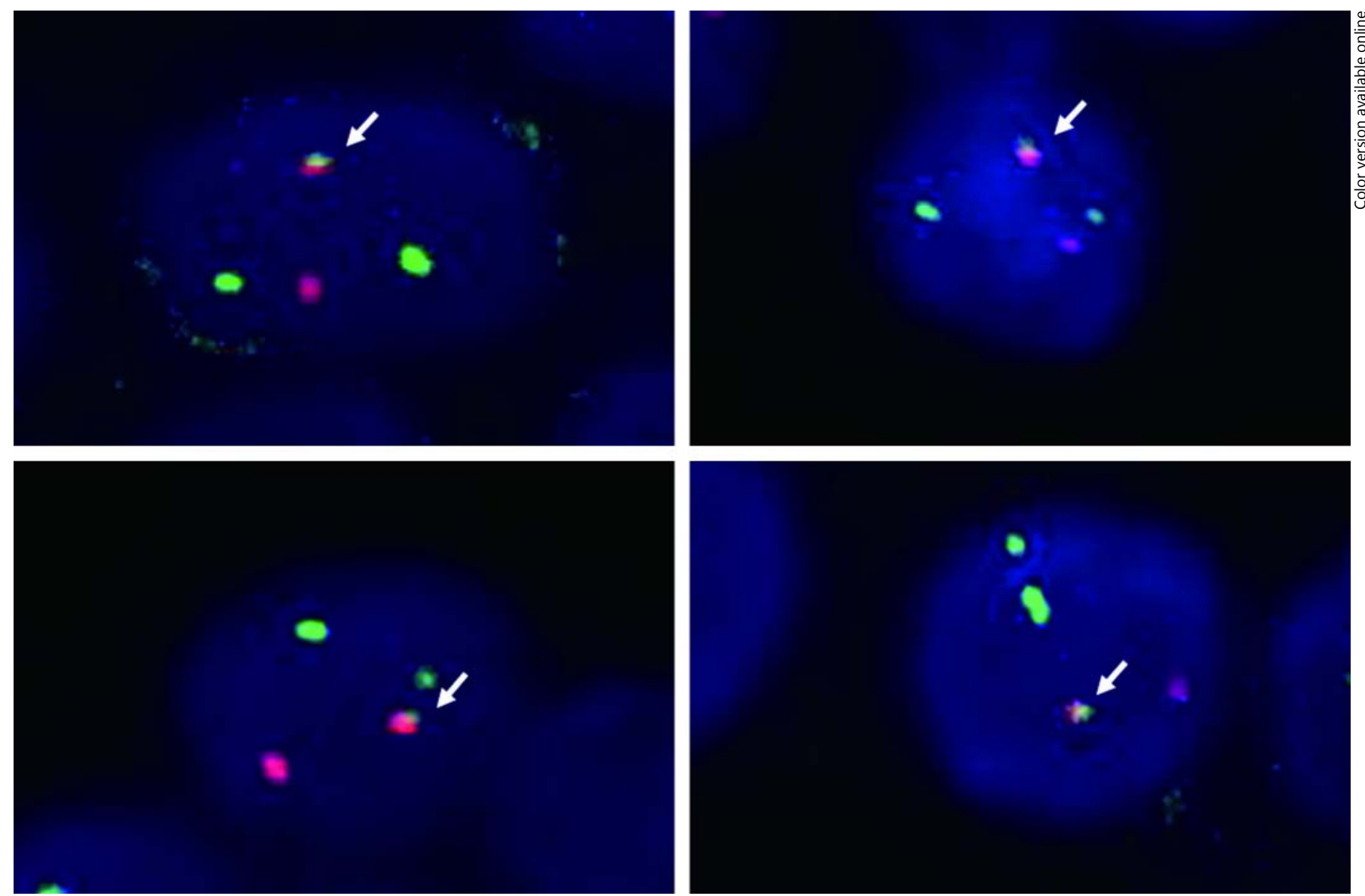

Fig. 3. $P M L-R A R a$ fusion gene detected by FISH in sample sections of the myeloid sarcoma. $P M L-R A R a$ dual-color fusion probes were used. $P M L-R A R a$ positive for $1 \mathrm{R} 2 \mathrm{G} 1 \mathrm{~F}$ (arrows), an atypical signal

pattern for the fusion gene distinguished from the typical 1R1G2F, was detected in $47 \%$ of the counted cells, indicating translocation of RARa on chromosome 17 into PML on chromosome 15.
Fig. 4. FLT3-TKD and WT1 point mutations detected in this case. A rare mutation of FLT3-TKD (Asp839Gly) and a novel mutation of WT1 (Arg458Pro) were recurrently detected during the treatment. Specimens for mutational analysis were from the preserved bone marrow film at the initial diagnosis, paraffin-coated testicular tissue with myeloid sarcoma, and the peripheral blood sample at EM relapse, respectively. The double peaks (arrows) demonstrate the point mutations. WT = Wild type; $\mathrm{M}=$ mutation; $\mathrm{JM}=$ juxtamembrane.

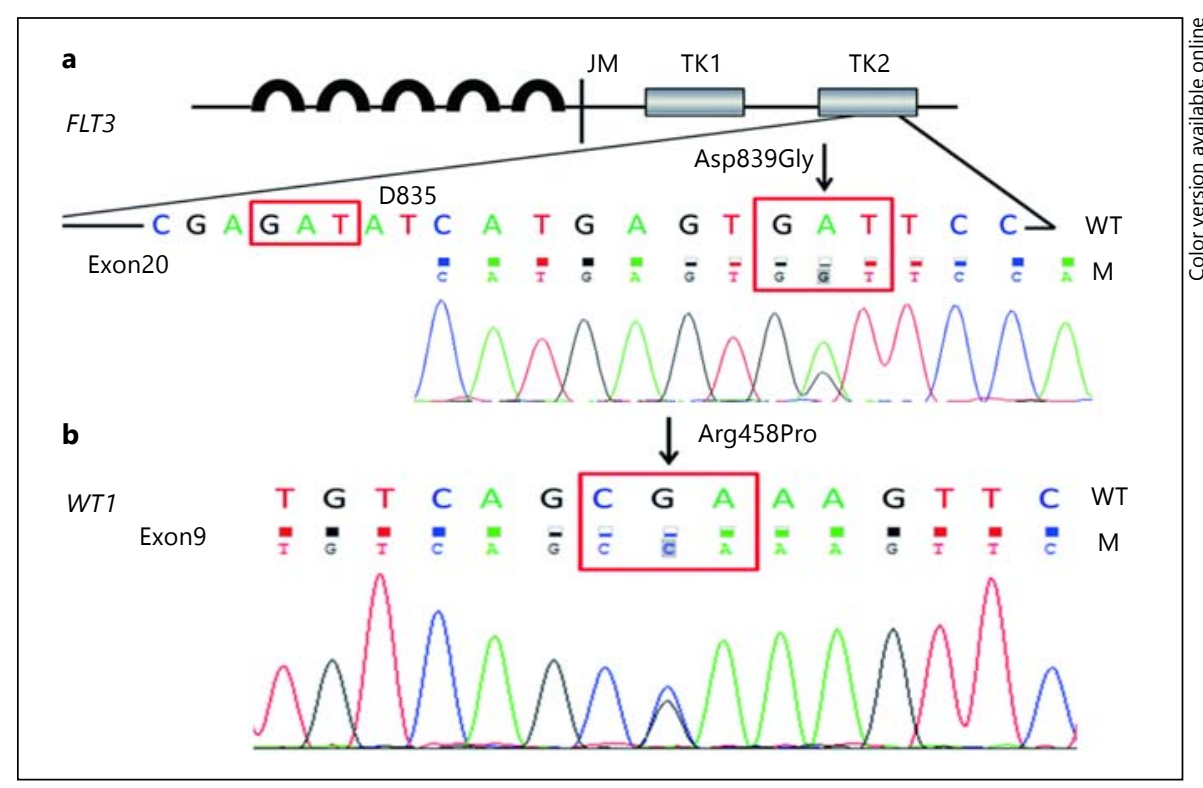


Table 1. APL patients with testicular relapse

\begin{tabular}{|c|c|c|c|c|}
\hline First author, year & Age, years & Regimens before relapse & Treatment of EMD & Prognosis \\
\hline Forrest, 1997 [10] & 34 & $\begin{array}{l}\text { HiAra-C+DNR, Ara-C+AMSA, Cis-RA, } \\
\text { Allo-HSCT }\end{array}$ & $\begin{array}{l}\text { Orchiectomy, } \\
\text { irradiation }\end{array}$ & Died in 2 years \\
\hline Milone, 1999 [11] & 41 & $\begin{array}{l}\text { ATRA, HiAra-C+MIT, ATRA+IDA, } \\
\text { VP-16, Allo-HSCT }\end{array}$ & Irradiation, DLI & - \\
\hline Gopal, 2005 [9] & 27 & (Primary myeloid sarcoma) & Orchiectomy & $\begin{array}{l}\text { Contralateral } \\
\text { relapse in } 1 \text { year }\end{array}$ \\
\hline Present study & 32 & ATRA, ATO+DNR, 6-MP, MTX & Orchiectomy & Second remission \\
\hline
\end{tabular}

documented sites of EM disease (EMD) are the central nervous system and skin [4], but other unusual places have also been reported [3, 5-8]. In total, only 3 patients have been reported with APL-associated testicular involvement to date (table 1). One patient manifested a solitary testicular mass at presentation [9], and the other two suffered from testicular relapse even after successful alloHSCT at 125 [10] and 69 months [11] from diagnosis, respectively, but no mutational analysis was performed during the treatment in these cases. By contrast, our case did not undertake HSCT and relapsed in a unilateral testicle long after the end of consolidation therapy. Moreover, this patient had an asymptomatic and painless swollen testicle more than half a year before systemic relapse, indicating that isolated EM abnormality may be the earliest clinical sign of systemic relapse of APL, in addition to prognostic factors that may be detected by mutational analysis. For this reason, any EM manifestations during therapy may be noteworthy for leukemic relapse, and risk-adapted therapy should be initiated in due time to block disease progression.

Some clinical characteristics have also been considered to correlate with EMD. According to a study involving 806 APL patients, EM relapse occurred more frequently in patients with high $\mathrm{WBC}$ counts (above $10,000 / \mathrm{mm}^{3}$ ) at diagnosis [4]. In other studies, treatment of APL with ATRA [12] and the occurrence of retinoic acid syndrome [13] were considered to predispose patients to EM relapse, but this was not proved by others [3]. Additionally, insufficient doses of cytotoxic drugs in ATRA-based regimens may fail to yield an effective concentration in the EM sites, which is also a possible contributor to subsequent relapse [14]. With respect to our case, although the remarkable leukocytosis at presentation might be responsible for EM

Testicular Relapse in APL with Flt3-TKD and WT1 Mutations recurrence in the patient, two genetic mutations have also been identified with a potential impact on the clinicobiological characteristics of APL. Two major forms of gainof-function mutations of FLT3, internal tandem duplication (ITD) and point mutations within the activation loop of the TKD were found in $21-38 \%$ and $9-20 \%$ of APL cases, respectively [15-20], among which Asp835Tyr (D835Y) is the most frequently detected FLT3-TKD (13.2\% in M5, $11.8 \%$ in M3v) mutation [21], resulting in constitutive tyrosine phosphorylation boosting neoplastic proliferation. Particularly in this patient, we detected a rare mutation, Asp839Gly (D839G) (fig. 3), which has not been previously reported in APL (but has been detected in 2 nonAPL patients [22]). D839 is located in the activation loop of FLT3-TKD2 and forms a hydrogen bond network together with adjacent amino acid residuals. However, the impact of D839G on conformational change of the activation loop leading to phosphatase activity variation of FLT3-TKD has not been studied. In addition, a novel WT1 mutation, Arg458Pro (c.1373G $>$ C), was also detected in our patient, but little is known about the prevalence of WT1 mutations and their significance in APL; the limited information was found in a recent report in which 4 out of 103 APL patients carrying WT1 mutations were predisposed to leukemia relapse [23]. Although WT1 mutations act as well-recognized indicators of a poor prognosis independently of chromosomal aberrations in AML [24], it is not the case for FLT3-TKD, and their prognostic significance in APL is still controversial [17, 20, 25, 26]. Most of the reports showed that some of these mutations are associated with inferior traits of APL. For example, FLT3-ITD mutations, with a higher incidence in $\mathrm{M} 3 \mathrm{v}$ and the $P M L$ $R A R a$ bcr3 isoform, are associated with a higher WBC count at diagnosis, resulting in a lower remission rate, 
higher induction-related mortality, and a lower 5-year overall survival rate $[15,19,21,25,26]$. However, there is little information about the correlation between genetic mutations and EMD in APL [27]; we could not exclude the possibility that the rare genetic mutations observed in this patient are relevant to his peculiar form of relapse and preferential site of myeloid sarcoma development.

With the diagnosis of testicular relapse, there is still a lack of standard therapy for this cohort of patients. Limited experience regarding treatment was acquired from several published case reports, in which patients received diverse or palliative approaches, including focal excision, radiotherapy on the involved field, and systemic administration of conventional agents combined with autologous or allo-HSCT. Novel agents such as gemtuzumab ozogamicin [8] and tamibarotene [7] may effectively induce a second remission. Unfortunately, our patient was randomly assigned to receive conventional therapy in the clinical trial of tamibarotene and missed a chance to verify this therapeutic option. However, cases of successful management of EMD with ATRA [28] and ATO [29] have also been previously published, and we thus still adminis- tered ATRA/ATO plus anthracyclines as the reinduction regimen after the clinical trial, resulting in a significant response of hematologic remission appropriate for HSCT.

In summary, we reported a case of unilateral testicle involvement as the sentinel manifestation of systemic relapse in a nontransplant APL patient with recurrent gene mutations, highlighting the importance of carefully monitoring EMD during follow-up, which might be a clinical marker of impending systemic relapse, and the risk stratification with mutational analysis for APL. However, further preclinical studies on these novel mutations and the interpretation of their different mutation statuses during APL progression are still warranted.

\section{Acknowledgement}

The authors are grateful to Dr. Hong-xing Liu, Department of Laboratory Medicine, Lu Daopei Hematology and Oncology Center, Beijing, China, for helpful discussions and technical assistance. We also thank Dr. Simrit Parmar, The University of Texas MD Anderson Cancer Center, Houston, Tex., USA, for assistance in language editing and professional advice.

\section{References}

1 Wang ZY, Chen Z: Acute promyelocytic leukemia: from highly fatal to highly curable. Blood 2008;111:2505-2515.

$\checkmark 2$ Niu C, Yan H, Yu T, Sun HP, Liu JX, Li XS, Wu W, Zhang FQ, Chen Y, Zhou L, Li JM, Zeng XY, Yang RR, Yuan MM, Ren MY, Gu FY, Cao Q, Gu BW, Su XY, Chen GQ, Xiong SM, Zhang TD, Waxman S, Wang ZY, Chen $\mathrm{Z}, \mathrm{Hu}$ J, Shen ZX, Chen SJ: Studies on treatment of acute promyelocytic leukemia with arsenic trioxide: remission induction, follow-up, and molecular monitoring in 11 newly diagnosed and 47 relapsed acute promyelocytic leukemia patients. Blood 1999;94: 3315-3324.

3 Specchia G, Lo Coco F, Vignetti M, Avvisati G, Fazi P, Albano F, Di Raimondo F, Martino B, Ferrara F, Selleri C, Liso V, Mandelli F: Extramedullary involvement at relapse in acute promyelocytic leukemia patients treated or not with all-trans retinoic acid: a report by the Gruppo Italiano Malattie Ematologiche dell'Adulto. J Clin Oncol 2001;19:4023-4028.

$\checkmark 4$ de Botton S, Sanz MA, Chevret S, Dombret H, Martin G, Thomas X, Mediavilla JD, Recher C, Ades L, Quesnel B, Brault P, Fey M, Wandt H, Machover D, Guerci A, Maloisel F, Stoppa AM, Rayon C, Ribera JM, Chomienne C, Degos L, Fenaux P: Extramedullary relapse in acute promyelocytic leukemia treated with all-trans retinoic acid and chemotherapy. Leukemia 2006;20:35-41.
5 Worch J, Ritter J, Fruhwald MC: Presentation of acute promyelocytic leukemia as granulocytic sarcoma. Pediatr Blood Cancer 2008;50: 657-660.

6 Ochs RCGR, Luger S, Bagg A: Isolated bowel relapse in acute promyelocytic leukemia: an unusual site of extramedullary recurrence. J Clin Oncol 2010;28:e550-e553.

7 Naina HV, Levitt D, Vusirikala M, Anderson LD Jr, Scaglioni PP, Kirk A, Collins RH Jr: Successful treatment of relapsed and refractory extramedullary acute promyelocytic leukemia with tamibarotene. J Clin Oncol 2011;29:e534-536.

${ }_{8}$ Tsimberidou AM, Estey E, Whitman GJ, Dryden MJ, Ratnam S, Pierce S, Faderl S, Giles F, Kantarjian HM, Garcia-Manero G: Extramedullary relapse in a patient with acute promyelocytic leukemia: successful treatment with arsenic trioxide, all-trans retinoic acid and gemtuzumab ozogamicin therapies. Leuk Res 2004;28:991-994.

9 Gopal S, Marcussen S, Dobin SM, Koss W, Donner LR: Primary myeloid sarcoma of the testicle with $\mathrm{t}(15 ; 17)$. Cancer Genet Cytogenet $2005 ; 157: 148-150$.

10 Forrest DL, Dalal BI, Naiman SC, Horsman DE, Berry BR, Parslow MI, Singh CP, Benny WB, Barnett MJ: Testicular relapse of acute promyelocytic leukemia after allogeneic BMT. Bone Marrow Transplant 1997;28:689-690.

11 Milone G, Inghilterra G, Li Gioi F, Peluso D, Giustolisi R: Testicular and cutaneous relapse after hematopoietic transplantation in a patient affected with APL. Bone Marrow Transplant 1999;23:751.

12 Wiernik PH, De Bellis R, Muxi P, Dutcher JP: Extramedullary acute promyelocytic leukemia. Cancer 1996;78:2510-2514.

13 Ko BS, Tang J, Chen YC, Yao M, Wang CH, Shen MC, Tien HF: Extramedullary relapse after all-trans retinoic acid treatment in acute promyelocytic leukemia - the occurrence of retinoic acid syndrome is a risk factor. Leukemia 1999;13:1406-1408

14 Ohno R, Asou N, Ohnishi K: Treatment of acute promyelocytic leukemia: strategy toward further increase of cure rate. Leukemia 2003;17:1454-1463.

15 Callens C, Chevret S, Cayuela JM, Cassinat B, Raffoux E, de Botton S, Thomas X, Guerci A, Fegueux N, Pigneux A, Stoppa AM, Lamy T, Rigal-Huguet F, Vekhoff A, Meyer-Monard S, Ferrand A, Sanz M, Chomienne C, Fenaux P, Dombret H: Prognostic implication of FLT3 and Ras gene mutations in patients with acute promyelocytic leukemia (APL): a retrospective study from the European APL Group. Leukemia 2005;19:1153-1160.

16 Kuchenbauer FSC, Kern W, Hiddemann W, Haferlach T, Schnittger S: Impact of FLT3 mutations and promyelocytic leukaemia-breakpoint on clinical characteristics and prognosis in acute promyelocytic leukaemia. Br J Haematol 2005;130:196-202. 
17 Barragan E, Montesinos P, Camos M, Gonzalez M, Calasanz MJ, Roman-Gomez J, Gomez-Casares MT, Ayala R, Lopez J, Fuster O, Colomer D, Chillon C, Larrayoz MJ, SanchezGodoy P, Gonzalez-Campos J, Manso F, Amador ML, Vellenga E, Lowenberg B, Sanz MA: Prognostic value of FLT3 mutations in patients with acute promyelocytic leukemia treated with all-trans retinoic acid and anthracycline monochemotherapy. Haematologica 2011;96:1470-1477.

18 Chillon MC, Santamaria C, Garcia-Sanz R, Balanzategui A, Sarasquete ME, Alcoceba M, Marin L, Caballero MD, Vidriales MB, Ramos F, Bernal T, Diaz-Mediavilla J, Garcia de Coca A, Penarrubia MJ, Queizan JA, Giraldo P, San Miguel JF, Gonzalez M: Long FLT3 internal tandem duplications and reduced PMLRARalpha expression at diagnosis characterize a high-risk subgroup of acute promyelocytic leukemia patients. Haematologica 2010; 95:745-751.

19 Gale RE, Hills R, Pizzey AR, Kottaridis PD, Swirsky D, Gilkes AF, Nugent E, Mills KI, Wheatley K, Solomon E, Burnett AK, Linch DC, Grimwade D: Relationship between FLT3 mutation status, biologic characteristics, and response to targeted therapy in acute promyelocytic leukemia. Blood 2005; 106:3768-3776.

20 Schnittger S, Bacher U, Haferlach C, Kern W, Alpermann T, Haferlach T: Clinical impact of FLT3 mutation load in acute promyelocytic leukemia with $\mathrm{t}(15 ; 17) /$ PML-RARA. Haematologica 2011;96:1799-1807.
21 Bacher U, Haferlach C, Kern W, Haferlach T, Schnittger S: Prognostic relevance of FLT3TKD mutations in AML: the combination matters - an analysis of 3,082 patients. Blood 2008;111:2527-2537.

22 Smith ML, Arch R, Smith LL, Bainton N, Neat M, Taylor C, Bonnet D, Cavenagh JD, Andrew Lister T, Fitzgibbon J: Development of a human acute myeloid leukaemia screening panel and consequent identification of novel gene mutation in FLT3 and CCND3. Br J Haematol 2005;128:318-323.

23 Gaur GC, Ramadan SM, Cicconi L, Noguera NI, Luna I, Such E, Lavorgna S, Di Giandomenico J, Sanz MA, Lo-Coco F: Analysis of mutational status, SNP rs16754, and expression levels of Wilms tumor 1 (WT1) gene in acute promyelocytic leukemia. Ann Hematol 2012;91:1855-1860.

24 Hou HA, Huang TC, Lin LI, Liu CY, Chen CY, Chou WC, Tang JL, Tseng MH, Huang CF, Chiang YC, Lee FY, Liu MC, Yao M, Huang SY, Ko BS, Hsu SC, Wu SJ, Tsay W, Chen YC, Tien HF: WT1 mutation in 470 adult patients with acute myeloid leukemia: stability during disease evolution and implication of its incorporation into a survival scoring system. Blood 2010;115:5222-5231.
25 Shih LY, Kuo MC, Liang DC, Huang CF, Lin TL, Wu JH, Wang PN, Dunn P, Lai CL: Internal tandem duplication and Asp835 mutations of the FMS-like tyrosine kinase 3 (FLT3) gene in acute promyelocytic leukemia. Cancer 2003;98:1206-1216.

26 Kutny MA, Moser BK, Laumann K, Feusner JH, Gamis A, Gregory J, Larson RA, Powell BL, Stock W, Willman CL, Woods WG, Meshinchi S: FLT3 mutation status is a predictor of early death in pediatric acute promyelocytic leukemia: a report from the Children's Oncology Group. Pediatr Blood Cancer 2012;59:662-667.

27 Tashiro H, Shirasaki R, Oka Y, Sugao T, Mizutani-Noguchi M, Yamamoto T, Akiyama N, Kawasugi K, Shirafuji N: FLT3 internal tandem duplication is associated with a high relapse rate and central nervous system involvement in acute promyelocytic leukemia cases: single institutional analysis. Eur J Haematol 2011;86:272-273.

28 Patriarca F, Fili C, Geromin A, Sperotto A, Prosdocimo S, Fanin R: Activity of all-transretinoic acid in a case of central nervous system extramedullary relapse of acute promyelocytic leukemia. Eur J Haematol 2002;68: 310-313.

29 Leoni F, Gianfaldoni G, Annunziata M, Fanci R, Ciolli S, Nozzoli C, Ferrara F: Arsenic trioxide therapy for relapsed acute promyelocytic leukemia: a bridge to transplantation. Haematologica 2002;87:485-489. 